\title{
O ENSINO DE FÍSICA NA PERSPECTIVA DE ALUNOS COM DEFICIÊNCIA VISUAL: ATIVIDADES QUE ABORDAM A RELAÇÃ̃ ENTRE OS CONCEITOS DE ATRITO E ACELERAÇÃO.
}

\section{EDUCATION OF PHYSICS, VISUAL DEFICIENCY AND PERTAINING TO SCHOOL INCLUSION: ACTIVITIES THAT APPROACH THE RELATION ENTER THE CONCEPTS OF ATTRITION AND ACCELERATION.}

\author{
Eder Pires de Camargo ${ }^{1}$ e Dirceu da Silva ${ }^{2}$ \\ ${ }^{1}$ Departamento de Física e Química, Faculdade de Engenharia, UNESPCampus de Ilha Solteira e \\ Programa de Pós-graduação em Educação para a Ciência (Área de Concentração: Ensino de Ciências) \\ Faculdade de Ciências, UNESP Campus de Bauru e-mail: camargoep@dfq.feis.unesp.br \\ ${ }^{2}$ Faculdade de Educação da Universidade Estadual de Campinas - UNICAMP e-mail: dirceu@unicamp.br \\ Apoio: FAPESP
}

\begin{abstract}
Resumo
Apresentamos a análise de duas atividades de ensino de física elaboradas e aplicadas a um grupo de alunos com deficiência visual. Durante a realização das atividades, os alunos tiveram a oportunidade de tocar vários tipos de materiais, descrever suas observações, relacioná-las à eventos cotidianos, propor problemas, apresentar hipóteses para a solução desses problemas, bem como, de ouvir explicações docentes e textos falados. Assim, a partir das análises efetuadas, concluiu-se que as atividades foram capazes de motivar os alunos e proporcionar aos mesmos, condições para que eles: (1) observassem propriedades do atrito por meio do tato; (2) relacionassem suas observações a eventos da vida cotidiana; (3) apresentassem e discutissem tais eventos; (4) formulassem e expusessem hipóteses durante a discussão dos referidos eventos; (5) ouvissem por meio do professor ou de textos falados modelos e sínteses relacionadas ao conceito de atrito e de aceleração. Tendo em vista a carência de material instrucional próprios para o ensino de física de alunos com deficiência visual, bem como, a urgência educacional que o referido tema exige, pretendese que os resultados aqui apresentados contribuam ao ensino de física de alunos com a citada deficiência.
\end{abstract}

Palavras-chave: ensino de física, deficiência visual, atividade de ensino.

\begin{abstract}
We present the analysis of two activities of elaborated and applied education of physics to a group of pupils with visual deficiency. During the accomplishment of the activities, the pupils had had the chance to touch some types of materials, to describe its comments, to relate them it the daily events, to consider problems, to present hypotheses for the solution of these problems, as well as, to hear teaching explanations and said texts. Thus, from the effected analyses, we conclude that the activities had been capable to motivate the pupils and to provide the same ones, conditions so that they: (1) they observed properties of the attrition by means of the tato; (2) the events of the daily life related its comments; (3) they presented and they argued such events; (4) they formulated and they displayed hypotheses
\end{abstract}


during the quarrel of the related events; (5) they heard by means of the professor or of said texts models and syntheses related to the acceleration and attrition concept. In view of the lack of instructional material proper for the education of physics of pupils with visual deficiency, as well as, the educational urgency that the related subject demands, we intend that the presented results contribute to the education of physics of pupils with the cited deficiency.

Key-word: education of physics, visual deficiency, activity of education.

\section{Discussão sobre a problemática investigada}

Este artigo apresenta resultados de uma pesquisa de doutorado concluída (Camargo, 2005) Na referida pesquisa avaliou-se atividades de ensino de física para alunos com deficiência visual. Para tal, elaborou-se um conjunto de cinco atividades de ensino do conceito "aceleração", conjunto este que se constituiu em um curso aplicado em dias consecutivos a um grupo de nove alunos cegos ou com baixa visão freqüentadores da instituição "Lar Escola Santa Luzia para Cegos", localizada na cidade de Bauru - SP. A formação escolar dos discentes variava de ensino fundamental incompleto, até ensino médio completo, passando por ensino fundamental completo e ensino médio incompleto. A idade dos alunos não era inferior a 16 anos e nem superior a 35 anos.

O curso foi estruturado em cinco aulas. A dinâmica das aulas abordou a aceleração e a desaceleração de um objeto, tendo como pano de fundo dois fatores causadores do referido fenômeno, o atrito e a gravidade. O conteúdo das atividades aqui apresentadas aborda os fenômenos de atrito e gravidade (primeira e segunda atividades do curso mencionado). A ordem de aplicação das atividades obedeceu ao seguinte critério: (a) a contextualização do fenômeno do atrito (atividade -1) e (b) o estabelecimento de relações entre o fenômeno do atrito e o fenômeno da aceleração (atividade-2). Na elaboração e condução das atividades, procurou-se considerar referenciais táteis e auditivos nos processos metodológicos de mediação e de observação dos fenômenos estudados. Dito de outro modo, a elaboração das atividades apoiou-se em três componentes práticos: tarefas, grupos e debates (WHEATLEY, 1991); e em três elementos de estrutura: interação com o objeto de estudo, resolução de problemas e confronto de modelos (Peres et. al. 1999). Assim, a partir da valorização de percepções não visuais em articulação com uma metodologia de ensino dialógico-participativa, construiu-se um ambiente interativo e 
comunicativo entre docente, discentes e conteúdo de ensino, ambiente este que se mostrou eficaz ao estabelecimento de relações argumentativas entre seus participantes, bem como, de condições perceptivas dos fenômenos estudados.

Em relação à metodologia, o trabalho aqui apresentado caracteriza-se como uma investigação qualitativa, pois, é a qualidade do retorno fornecido pelos alunos devido ao processo que constituiu a atividade aplicada que configura o aspecto mais importante dos dados coletados (LUDKE, ANDRÉ, 1986, MORALES, MORENO, 1993). Como as informações acerca do fenômeno educacional observado surgiram em um contexto dinâmico de relações, a coleta de informações por meio de gravações sonoras e visuais e anotações feitas pelo pesquisador revelaram o caráter descritivo dos dados coletados, e se mostrou muito útil para sua análise, que possuiu um aspecto nitidamente qualitativo, centrada nas qualidades das falas e dos processos que os alunos apresentaram e foram submetidos. Na seqüência, apresentam-se as atividades de ensino.

\section{As atividades}

\section{Atividade (1): observação e contextualização do fenômeno do atrito.}

Objetivo: proporcionar oportunidades para que alunos com deficiência visual reconheçam tatilmente diferentes objetos e superfícies, a fim de contextualizar o estudo do fenômeno do atrito.

\section{Materiais a serem utilizados:}

(Kit-1): (a) bichos de pelúcia, tapetes, carpetes, diferentes tipos de toalhas plásticas e os seguintes tecidos: veludo, tecido felpudo e flanela. Cada material citado foi cortado em um tamanho aproximado de $0,5 \mathrm{~m}$ de comprimento por $0,5 \mathrm{~m}$ de largura; (b) lixas e palha de aço.

\section{Procedimentos:}

I. Interação e observação do fenômeno: deixar os alunos tocarem os vários tipos de objetos do kit - 1, bem como, esfregarem um objeto ao outro. Dessa forma, eles poderão perceber tatilmente o quanto esses objetos são lisos, macios, ásperos, e as diferentes interações provenientes dos contatos entre os diversos tipos de materiais. Pretende-se com 
este procedimento, contextualizar o tema "atrito" a fim de que situações da vida cotidiana desses alunos relacionadas ao referido tema venham a tona e sejam discutidas.

II. Trabalhando em grupo: a) solicitar aos alunos para que em grupo discutam as diferenças e semelhanças observadas tatilmente entre os objetos do kit - 1, e entre as interações provenientes dos contatos desses objetos; b) solicitar aos alunos para que, em grupo, discutam situações de seus cotidianos onde estejam presentes questões relacionadas com as características observadas, ou seja, com o atrito; c) solicitar aos alunos para que, em grupo, discutam situações onde o atrito pode ser encarado como necessário ou desnecessário. Neste momento da atividade, o professor estará atendendo os grupos no sentido de prestar-lhes auxílio quanto ao esclarecimento de possíveis dúvidas e quanto ao direcionamento das discussões propostas.

III. O debate: após os alunos terem discutido em grupo as questões sugeridas, solicitar para que cada grupo exponha suas conclusões. Tal exposição deverá estar aberta à discussão ou intervenção de outros alunos do grupo ou de fora do grupo.

\section{Mediação do professor:}

Apresentar e discutir com os alunos o texto (1), "Entre tapas e beijos" gravação disponível em: http://www.fc.unesp.br/pos/ciclos/index.htm (clicar em Download e depois no arquivo áudio1.mp3).

"Na Física, a idéia de contato está relacionada à interação que surge quando objetos se tocam. Podemos entender essa idéia se pensarmos em nosso próprio corpo. Ele está equipado para sentir estas interações, que podem se manifestar sob as mais diferentes formas, produzindo uma grande variedade de sensações em nossa pele. Uma boa bofetada, por exemplo, corresponde a uma interação entre a mão de quem bate e a face de quem recebe, assim como um carinho. Do ponto de vista da Física essas duas interações são de mesma natureza. Uma diferença básica entre elas é a intensidade da força aplicada: um tapa, em geral, significa uma força muito mais intensa do que um carinho. Porém há outra diferença importante entre o tapa e o carinho: a direção da força aplicada. Em um tapa, a força é na direção perpendicular à face da vítima e no carinho, em geral, essa força ocorre numa direção paralela à pele. Essa distinção também ocorre em outras situações em que existe o contato entre os objetos. Em batidas, chutes, pancadas, beijos, espetadas, ou mesmo simplesmente quando um objeto se apóia sobre outro, temos forças que agem na direção perpendicular ou normal à superfície dos objetos e por isso são denominadas forças normais. Em outros casos, a força aparece na direção paralela à superfície. É o que ocorre em situações como arranhões, raspadas, esfregadas, deslizamentos, etc. Em geral, essas forças recebem o nome de forças de atrito. Portanto, os efeitos das forças de contato entre objetos dependem da maneira como são aplicadas, paralela ou 
perpendicular à superfície. Mas não é só isso que influi. Também são importantes: a intensidade da força, as características dos objetos e de suas superfícies, e o tempo em que eles permanecem em contato" (COPELLI et. al., 1998).

\section{Atividade (2): o atrito e o conceito de desaceleração.}

\section{Problema central da atividade:}

Quais são os principais fatores que influenciam o movimento do bloco? O "peso" do objeto é importante? Seu formato é importante? Ambos são importantes? Como podemos descobrir?

Objetivos: a) compreender o atrito como resultado do contato e do deslizamento de uma superfície sobre outra e b) observar tatilmente o comportamento do movimento de blocos de madeira sobre superfícies de diferentes polimentos (o conceito de desaceleração).

\section{Materiais a serem utilizados:}

(Kit - 2) - (a) três superfícies, sendo uma áspera como uma lixa, outra bem lisa, e outra com um polimento intermediário; (b) blocos de madeira em formato de paralelepípedo, de mesmas superfícies, e diferentes massas. Obs: sugere-se que as massas dos blocos sejam de aproximadamente: $100 \mathrm{~g}, 300 \mathrm{~g}$, e $500 \mathrm{~g}$.

(Kit - 3) - uma maquete contendo: (a) uma superfície muito enrugada para representar macroscopicamente superfícies; (b) um objeto enrugado (maquete-1) tanto a superfície quanto o objeto, devem permitir ao aluno com deficiência visual observar com o tato suas saliências.

(Kit - 4) - uma maquete contendo: (a) um pedaço de um cabo de vassoura de $30 \mathrm{~cm}$ de comprimento, fixo perpendicularmente a uma pequena tábua de $30 \mathrm{~cm}$ de comprimento por $20 \mathrm{~cm}$ de largura. Com este objeto, pretende-se representar uma reta normal a uma superfície. (b) Três pedaços de madeira de $5 \mathrm{~cm}$ de largura por $15 \mathrm{~cm}$ de comprimento, fixos paralelamente a uma pequena tábua de $30 \mathrm{~cm}$ de comprimento por $20 \mathrm{~cm}$ de largura (maquete-2). Pretende-se com este objeto, representar retas paralelas. Este material objetiva contribuir para a construção dos conceitos de força normal e de força de atrito, visto que, utiliza-se de um referencial tátil para a observação de retas dispostas perpendicularmente e paralelamente. 


\section{Procedimentos:}

I. Interação e observação do fenômeno: empurrar os diferentes blocos de madeira do kit -2 em diferentes posições sobre as superfícies lisas e ásperas, e observar tatilmente o que ocorre com o movimento desses blocos nas diferentes superfícies.

II. Trabalhando em grupo. Em grupo, explique: a) que ações podem ser realizadas sobre os blocos de madeira do kit - 2 para movê-los? O "peso" do bloco é importante? Seu formato é importante? Ambos são importantes? Como podemos descobrir? b) Qual é a relação entre as diferenças no peso dos objetos e as diferenças em sua mobilidade?

III. O debate: proporcionar um debate entre os grupos, para que os mesmos possam apresentar suas conclusões sobre o fenômeno observado. Durante este debate, o professor poderá apresentar os argumentos científicos sobre o tema em questão, atuando dessa forma, como mais um grupo participante da discussão.

IV. Mediação do professor: o professor poderá apresentar os argumentos científicos utilizando-se da maquete do atrito (maquete-1), e do texto (2) (texto sobre o atrito) previamente gravado. A gravação encontra-se disponível em: http://www.fc.unesp.br/pos/ciclos/index.htm (clicar em Download e depois no arquivo áudio3.mp3).

Para iniciarmos o movimento de um bloco que está apoiado sobre uma superfície, sentimos certa resistência. Geralmente, assim que o movimento do bloco se inicia, essa resistência diminui. Isto ocorre, pois, quando fazemos a superfície de um corpo escorregar sobre a de outro, cada corpo exerce sobre o outro, uma força paralela às superfícies. Essa força é denominada Força de Atrito. A força de atrito sobre cada corpo tem sentido oposto ao seu movimento em relação ao outro corpo, e dessa forma, as forças de atrito se opõe ao movimento, nunca o favorecem.

Em nosso dia a dia, o atrito exerce uma função fundamental. O movimento de um carro, por exemplo, só é possível porque existe uma força na direção e no sentido do movimento do mesmo. O processo é basicamente o seguinte: a queima do combustível no motor provoca o movimento de pistões que é transmitido para as rodas, e consequentemente para os pneus. Esses, através de uma força de contato empurram o chão para traz (ação) e o chão empurra o carro para frente (reação). Sem essa reação que também é uma força de contato ou de atrito, o carro não sairia do lugar e os pneus deslizariam sobre o asfalto. Se não houvesse o atrito, ou seja, se tudo fosse muito liso e escorregadio, caminhadas, corridas, passeios de carro, de ônibus etc., se tornariam quase que impraticáveis. Segurar um punção ou mesmo ler um texto em Braille seriam tarefas complexas.

A força de atrito entre um par qualquer de superfícies secas, não lubrificadas, obedece a duas leis empíricas: 
1) É aproximadamente independente da área de contato, dentro de amplos limites.

2) É proporcional à força normal.

Vamos tentar entender a força normal analisando um caixote cheio de areia sobre uma mesa. O caixote, sob a ação da gravidade, (Força Peso) é comprimido contra a superfície da mesa, Que reage com uma força igual em intensidade, mas em sentido contrário, denominada força normal. Assim, a força normal é uma força perpendicular à superfície de apoio, exercida por esta ao objeto.

Do ponto de vista macroscópico, a área real de contato entre dois objetos é muito pequena, limitando-se a alguns pontos. Sendo assim, a pressão nesses pontos é bastante grande, o que provoca a união dessas pequenas regiões. $\mathrm{Na}$ maquete do atrito representamos em detalhe a área de contato entre um caixote e uma mesa. Observe que o contato ocorre apenas em pequenas regiões da base do caixote. $\mathrm{O}$ atrito surge da necessidade de quebrar essas uniões quando se tenta fazer um objeto deslizar sobre outro. Iniciado o deslizamento, as uniões já existentes são quebradas e outras são formadas.

O que diferencia uma determinada superfície de outra, é a natureza dessa superfície, bem como, sua condição de polimento e de lubrificação. Entretanto, como representado na maquete, ao nível atômico, mesmo a superfície mais cuidadosamente polida está longe de ser plana. Portanto, $\mathrm{O}$ atrito depende da natureza, do grau de polimento dos materiais que formam os objetos, e da lubrificação entre eles. Se as superfícies de contato forem polidas e lubrificadas, a intensidade dos contatos nas uniões será menor, diminuindo a força de atrito. Dessa forma, para atenuar os efeitos do atrito costuma-se colocar lubrificantes entre as duas superfícies, pois, os óleos diminuem os números de uniões entre as mesmas (RESNICK E HALLIDAY, 1984 e GONÇALVES E TOSCANO, 1997).

V. Avaliação - Responda: como uma pessoa, em repouso sobre a superfície gelada e muito lisa de um lago, poderia alcançar a margem? (RESNICK E HALLIDAY, 1984).

Os textos (1) e (2), bem como, o problema inicial e a questão avaliação da atividade (2) foram gravados e apresentados aos alunos por meio de um toca Cd. Observa-se que as gravações foram realizadas em um estúdio e fazem parte de um $\mathrm{Cd}$ que além das referidas gravações contém as de outros problemas e questões. As informações completas do CD encontram-se disponíveis em: http://www.fc.unesp.br/pos/ciclos/index.htm (clicar em Download e depois nos arquivos áudio. mp3).

\section{Definição das categorias para a análise das atividades aplicadas.}

Visando analisar se a estrutura metodológica e os materiais das atividades (1) e (2) proporcionaram condições para que os alunos com deficiência visual participassem de um ambiente de aprendizagem (BAUERSFELD, 1988), elaborou-se a categoria compreensão. A referida categoria fundamentou-se em elementos que indicam quatro atitudes (compartilhar, questionar, defender, reformular) adotadas ou não pelos alunos para a 
compreensão de um determinado fenômeno. Esses elementos denominados: "elementos de compreensão", encontram-se na seqüência relacionados.

I. Compartilhou hipóteses: este elemento de compreensão refere-se à atitude de um aluno em compartilhar uma determinada hipótese com outros alunos durante a discussão de um determinado problema. Considera-se que a hipótese compartilhada pode ter sido elaborada ou não pelo aluno que a expressou.

II. Questionou hipóteses: este elemento de compreensão refere-se à atitude de um aluno em questionar uma determinada hipótese defendida por outro aluno.

III. Defendeu hipóteses: este elemento de compreensão refere-se à atitude de um aluno em defender uma determinada hipótese de hipóteses rivais, apresentadas por outros alunos.

IV. Reformulou hipóteses: este elemento de compreensão refere-se à atitude de um aluno em reformular uma hipótese passando a compartilhar outra.

\section{Análise da Aplicação das Atividades}

$\mathrm{Na}$ análise os alunos serão identificados pelas letras: (A) (B) (C) (D) (E) (F) (G) (H) e (I). Participaram da atividade (1) todos os alunos considerados, enquanto que da atividade (2), não participou o aluno (E).

\section{Análise da atividade (1).}

Tendo em vista a contextualização do fenômeno do atrito, na primeira parte da atividade (1) (momento de interação com o fenômeno estudado), os alunos puderam reconhecer sobre o referencial tátil, diferenças entre objetos e superfícies. Para tanto, os alunos tinham a disposição para serem tocados, os materiais do kit - 1. No início da atividade, o professor organizou os alunos em três grupos, e entregou a cada grupo um kit 1. Os grupos foram formados aleatoriamente como indicado na sequiência: o grupo (1) foi formado pelos alunos A, B e I, o grupo (2) foi formado pelos alunos C, D e G, e o grupo (3) foi formado pelos alunos E, F e H. Após a formação dos grupos e da distribuição dos kits 1, o professor solicitou aos alunos para que observassem os materiais por meio do tato, esfregando as mãos sobre os mesmos, deslizando um sobre o outro, identificando dessa forma, diferenças e semelhanças entre eles. 
O momento de interação descrito mostrou-se adequado para o estabelecimento de um contato inicial entre os alunos e algumas propriedades do atrito. Ao descreverem os materiais, os alunos utilizavam-se de palavras como: "áspero, liso, agressivo, desliza, antiderrapante, aderência, gruda, raspa, atrita", que indicam que determinadas propriedades relacionadas ao atrito estavam sendo observadas e começavam a ser discutidas por eles. Tais palavras foram fundamentais para o estabelecimento de um conjunto conceitual inicial, conjunto este que facilitou a apresentação por parte dos alunos de hipóteses explicativas para problemas que surgiram durante o debate, além de proporcionar ao professor, condições para o aprofundamento do tema. Foi por meio da utilização das palavras descritas, que o professor deu seqüência à atividade (1), sugerindo a problematização do atrito em função de experiências cotidianas vividas pelos alunos.

Após os alunos terem participado do momento de interação, iniciou-se um segundo momento caracterizado por um debate sobre o fenômeno do atrito. Neste momento da atividade (1), o professor solicitou inicialmente aos alunos, para que relacionassem suas observações a situações cotidianas, e depois para que abordassem qualitativamente o atrito em função de suas utilidades práticas. Devido às solicitações do professor os alunos se envolveram em um debate acerca do atrito no qual um "conjunto conceitual" foi utilizado por eles em suas argumentações. Esse "conjunto conceitual" que pode ser identificado nas relações entre causa e efeito estabelecidas pelos alunos em suas declarações, é explicitado aqui de forma sintética por seis proposições denominadas "hipóteses". Tais hipóteses, portanto, representam uma síntese dos conceitos que fundamentaram as argumentações utilizadas pelos alunos. Na seqüência, apresentam-se as hipóteses identificadas e algumas das declarações dos alunos que justificam uma determinada hipótese.

\section{Hipóteses utilizadas pelos alunos durante o debate da atividade (1).}

Apresentam-se na sequiência, as hipóteses utilizadas pelos alunos durante o debate. Observa-se que devido ao limite do espaço para a apresentação desse artigo, não foi possível a disposição de todas as declarações dos alunos, contudo, abaixo de cada hipótese, apresenta-se ao menos uma declaração de cada aluno que se utilizou da mesma durante o debate. As declarações não se encontram necessariamente dispostas de acordo com uma sequiência cronológica de acontecimento. Observa-se que por motivos de organização da 
análise, as declarações encontram-se enumeradas. A presente observação também é válida para as hipóteses que serão apresentadas por ocasião da análise da atividade (2). Destaca-se que cada hipótese será identificada pela sigla (m.n) onde (m) representa a atividade e (n) representa a ordem da hipótese.

\section{(1.1) O atrito resulta do contato entre duas superfícies. $O$ polimento e as} características dos materiais que constituem tais superfícies interferem na intensidade do atrito.

1) A: Dependendo do calçado e do tipo de superfície que você está pisando, você consegue uma aderência ou está numa situação bem escorregadio.

2) C: Imaginem uma roupa de ceda num banco de plástico, escorrega muito.

3) D: Com este chinelo gasto o chão fica totalmente derrapante

4) E: Roupa fina perde a aderência com o banco de ônibus.

5) F: Se você pisar numa superfície de supermercado com este chinelo gasto é capaz de você cair.

6) G: Tem calçado, que depende o piso, se é cimento brusco, já é fácil de você andar, agora se é um cimento queimado, ele já fica liso e ai depende do calçado que você usa.

7) H: No piso liso o pano de chão desliza rapidinho, mais ele não corre no piso antiderrapante.

8) I: Com Rasteirinha (um tipo de calçado feminino) a gente escorrega bastante.

\section{(1.2) Produtos como a cera ou a água diminuem o atrito entre duas superfícies.}

9) A: O chão do supermercado é liso, eles enceram muito, todos os dias, ai não da aderência.

10) C: Mas se passar cera pode prejudicar os próprios materiais do supermercado se alguém cair e derrubar tudo. (questionamento do aluno C à hipótese (3))

11) D: Se você passar cera o atrito diminui

12) E: a cera é uma maneira de lubrificar o piso

13) G: Minha irmã passa uma cera na geladeira e a gente sempre coloca aqueles bichinhos lá (imã) e quando passa a cera aqueles bichinhos lá não param!

14) H: Nossa! Com cera o chão fica liso!

\section{(1.3) Produtos como a cera podem aumentar o atrito entre duas superfícies.}

15) F: É bom passar cera até para a própria segurança do material deles lá no supermercado. (declaração motivo de questionamento por parte do aluno $(C)$.

\section{(1.4) Um atrito pequeno facilita o movimento de objetos sem rodas.}

16) A: Se o cara estiver nadando como um peixe na água, ele precisa ir cada vez. mais veloz, se tiver menos atrito para segurar ele é melhor.

17) E: Quem anda de patins (sem rodas) tem que ter pouco atrito, e aqui ele (o baixo atrito) é positivo, em função de quem desliza sobre o piso. (declaração que recebeu questionamento do aluno $(F)$ por meio da hipótese (5). 
18) G: No caso da natação o atrito baixo é bom.

19) H: Todo nadador você pode ver que ele depila, porque o pelo dá atrito, ele adere na água.

\section{(1.5) Um pequeno atrito dificulta o movimento de objetos sobre rodas.}

20) A: Na fórmula 1 a gente vê que de acordo com a pista, os engenheiros desenvolvem um composto de borracha para dar mais atrito, eles sempre buscam o melhor atrito, a melhor aderência.

21) B: Com pouco atrito o carro perde a aderência.

22) C: Para o caso de uma pista se o atrito for baixo ele (o carro de corrida) vai deslizar, derrapar.

23) F: Se o atrito for muito baixo o patins (com rodas) não para na lateral! (declaração do aluno $(F)$ que questiona a hipótese (4).

24) G: Imagine um carro com o pneu careca entrando na garagem que tem esses pisos frios (ladrilho), se o piso estiver molhado veja se ele entra!

25) H:É igual o carrinho de rolimã, acho que tem que ser mais alto o atrito dele, não é?

26) I: Imagine um carro no brejo, roda em falso.

\section{(1.6) O peso aumenta 0 atrito.}

27) E: Quanto maior o peso maior o atrito.

28) F: Outra coisa, muito peso aumenta o atrito, porque um carro se ele com a rotatividade do motor e ele pesar 200kg, com a capacidade do giro do motor ele não conseguiria andar.

\section{A atividade (1) enquanto ambiente de ensino-aprendizagem.}

Analisando as hipóteses da atividade (1) à luz da categoria compreensão, pode-se explicitar as características das atitudes de compreensão utilizadas pelos alunos durante o debate. O quadro (1) apresenta uma relação entre cada hipótese e as atitudes de compreensão adotadas pelos alunos durante o debate.

\begin{tabular}{|c|c|c|c|c|c|c|c|c|c|}
\hline Alunos & $\mathbf{A}$ & B & $\mathbf{C}$ & D & $\mathbf{E}$ & $\mathbf{F}$ & $\mathbf{G}$ & $\mathbf{H}$ & I \\
\hline (1.1) & Compartilhou & $\begin{array}{c}\text { Não } \\
\text { demonstrou } \\
\text { atitudes }\end{array}$ & Compartilhou & Compartilhou & Compartilhou & Compartilhou & Compartilhou & Compartilhou & Compartilhou \\
\hline (1.2) & Compartilhou & $\begin{array}{c}\text { Não } \\
\text { demonstrou } \\
\text { atitudes }\end{array}$ & Compartilhou & Compartilhou & Compartilhou & $\begin{array}{c}\text { Não } \\
\text { demonstrou } \\
\text { atitudes }\end{array}$ & Compartilhou & Compartilhou & $\begin{array}{c}\text { Não } \\
\text { demonstrou } \\
\text { atitudes }\end{array}$ \\
\hline 1.3) & $\begin{array}{c}\text { Não } \\
\text { demonstrou } \\
\text { atitudes }\end{array}$ & $\begin{array}{c}\text { Não } \\
\text { demonstrou } \\
\text { atitudes }\end{array}$ & $\begin{array}{l}\text { Questionou } \\
\text { por meio da } \\
\text { hipótese (2) }\end{array}$ & $\begin{array}{c}\text { Não } \\
\text { demonstrou } \\
\text { atitudes }\end{array}$ & $\begin{array}{c}\text { Não } \\
\text { demonstrou } \\
\text { atitudes }\end{array}$ & Compartilhou & $\begin{array}{c}\text { Não } \\
\text { demonstrou } \\
\text { atitudes }\end{array}$ & $\begin{array}{c}\text { Não } \\
\text { demonstrou } \\
\text { atitudes }\end{array}$ & $\begin{array}{c}\text { Não } \\
\text { demonstrou } \\
\text { atitudes }\end{array}$ \\
\hline (1.4) & Compartilhou & $\begin{array}{c}\text { Não } \\
\text { demonstrou } \\
\text { atitudes }\end{array}$ & $\begin{array}{c}\text { Não } \\
\text { demonstrou } \\
\text { atitudes }\end{array}$ & $\begin{array}{c}\text { Não } \\
\text { demonstrou } \\
\text { atitudes }\end{array}$ & Compartilhou & $\begin{array}{l}\text { Questionou } \\
\text { por meio da } \\
\text { hipótese }(5)\end{array}$ & Compartilhou & Compartilhou & $\begin{array}{c}\text { Não } \\
\text { demonstrou } \\
\text { atitudes }\end{array}$ \\
\hline (1.5) & Compartilhou & Compartilhou & Compartilhou & $\begin{array}{c}\text { Não } \\
\text { demonstrou } \\
\text { atitudes }\end{array}$ & $\begin{array}{l}\text { Questionou } \\
\text { por meio da } \\
\text { hipótese (4) }\end{array}$ & $\begin{array}{l}\text { Compartilhou } \\
\text { e defendeu }\end{array}$ & Compartilhou & Compartilhou & Compartilhou \\
\hline 1.6) & $\begin{array}{c}\text { Não } \\
\text { demonstrou } \\
\text { atitudes }\end{array}$ & $\begin{array}{c}\text { Não } \\
\text { demonstrou } \\
\text { atitudes }\end{array}$ & $\begin{array}{c}\text { Não } \\
\text { demonstrou } \\
\text { atitudes }\end{array}$ & $\begin{array}{c}\text { Não } \\
\text { demonstrou } \\
\text { atitudes }\end{array}$ & Compartilhou & Compartilhou & $\begin{array}{c}\text { Não } \\
\text { demonstrou } \\
\text { atitudes }\end{array}$ & $\begin{array}{c}\text { Não } \\
\text { demonstrou } \\
\text { atitudes }\end{array}$ & $\begin{array}{c}\text { Não } \\
\text { demonstrou } \\
\text { atitudes }\end{array}$ \\
\hline
\end{tabular}


Quadro (1): Relação para a atividade (1) entre as hipóteses e as atitudes definidas na categoria compreensão.

Das seis hipóteses identificadas, as hipóteses (1.1) (1.2) (1.4) e (1.5), mostraram-se significativas entre os alunos. As hipóteses (1.3) e (1.6) se mostraram muito menos significativas entre os alunos, já que foram utilizadas em momentos isolados dentro do debate. Dessa forma, entende-se que os alunos ao apresentarem suas explicações aos problemas decorrentes do debate, apoiavam-se fortemente nas idéias de que: $\mathrm{O}$ atrito é resultado do contato entre superfícies. Sua intensidade depende do polimento e da natureza dos materiais que constituem tais superfícies, bem como da lubrificação entre as mesmas, lubrificação esta que juntamente com o polimento, diminuem o atrito e facilitam o movimento (hipóteses: 1.1, 1.2, 1.4, e 1.5). A idéia de que o peso aumenta o atrito (hipótese-1.6), e por consequiência, dificulta o movimento, apesar de não ter sido compartilhada de uma maneira significativa, não recebeu questionamentos. Já a idéia de que produtos como a água ou a cera podem aumentar o atrito (hipótese-1.3) além de não ter sido compartilhada por mais de um aluno (aluno F), recebeu por parte do aluno (C) questionamentos fundamentados na idéia contida na hipótese (1.2), hipótese esta significativamente compartilhada (Comparar frases: 10x15). Assim, enquanto ambiente de ensino aprendizagem a atividade (1), mostrou-se capaz de contextualizar o fenômeno do atrito e gerar discussões fundamentadas em compartilhamentos de conceitos comuns aos alunos. Por outro lado, a referida atividade mostrou-se menos eficaz em produzir significativos momentos de questionamentos defesas e reformulações de hipóteses, fato este que se deveu ao seu objetivo principal que foi a contextualização do fenômeno do atrito, objetivo este que determinou sua elaboração.

Um momento denominado: "momento de apresentação de modelos, sínteses e conclusões" finalizou a atividade (1). O professor buscando apresentar modelos científicos relacionados ao surgimento do atrito e uma organização dos temas discutidos utilizou-se de um toca CD para apresentar aos alunos o texto falado (texto-1). Por meio dos eventos cotidianos "tapa" e "carinho" abordados no referido texto, foram apresentados dois tipos de Interação entre superfícies, a interação perpendicular à superfície (tapa), e a interação paralela à superfície (carinho). Pegando nas mãos dos alunos e interagindo-as com a mesa das maneiras descritas, ou seja, batendo-as levemente e esfregando-as à mesa, ele 
apresentou aos alunos, as definições de "perpendicular" e "paralelo", relacionando a primeira ao conceito de "força normal" e a segunda ao de "força de atrito". Observou-se que durante a fala do texto, os alunos se mostravam muito atentos e concentrados ao seu conteúdo. Ao final da fala do texto, e das explicações do professor encerrou-se a atividade (1).

Em síntese, conclui-se que a atividade (1) enquanto ambiente de ensinoaprendizagem, foi capaz de proporcionar aos alunos condições para que os mesmos: (1) observassem propriedades do atrito por meio do tato; (2) relacionassem suas observações a eventos da vida cotidiana; (3) apresentassem e discutissem tais eventos; (4) formulassem e expusessem hipóteses durante a discussão dos referidos eventos; (5) ouvissem por meio do professor ou do texto falado "Entre tapas e beijos" modelos e sínteses relacionadas ao conceito de atrito. Dessa forma, a atividade (1) ao contextualizar o fenômeno do atrito, proporcionou condições adequadas para que uma discussão mais aprofundada sobre este assunto pudesse ser feita, discussão esta que foi reservada para a atividade (2).

\section{Análise da atividade (2).}

No início da atividade (2) (momento de experimentação) o professor dividiu os alunos em três grupos que ficaram constituídos da seguinte maneira - grupo (1): alunos (A) (B) e (I); grupo (2): alunos (C) (D) e (G); grupo (3): alunos: (F) e (H). Depois da formação dos grupos, o professor objetivando retomar a discussão dos conceitos de "força normal" e "força de atrito", conceitos estes trabalhados no final da atividade (1), distribuiu a cada grupo um kit - 4. O professor com o auxílio do referido quite e tocando nas mãos dos alunos, explicou-lhes novamente os conceitos de "reta normal" e "retas paralelas", relacionando o primeiro ao conceito de "força normal" e o segundo ao de "força de atrito". Portanto, por meio do texto falado (texto-1) apresentado na atividade (1) e do kit - 4, os alunos conseguiram refletir acerca dos conceitos de reta normal e retas paralelas. Dessa forma, a utilização do referido quite no início da atividade (2), representou a partir de um referencial tátil, a retomada da discussão sobre o atrito, discussão esta contextualizada na atividade (1).

Dando prosseguimento, o professor distribuiu aos grupos o kit - 2 e ligou o toca CD no problema central da atividade (2). Depois o professor solicitou aos alunos para que 
interagissem com os materiais do kit - 2. Os alunos, objetivando apresentar soluções ao problema central, movimentaram de várias maneiras os blocos de diferentes massas sobre as diferentes superfícies. Exemplo: com as mãos constantemente sobre os blocos fazendo um tipo de vai e vem, empurrando e tirando as mãos, mudando o lado de contato com a superfície de apoio, fazendo os blocos passar de uma superfície para outra. Portanto, o momento de experimentação se mostrou eficaz sobre o ponto de vista da realização de experimentos, da concentração, do interesse, e da comunicação entre os alunos, além de proporcionar as condições adequadas para a realização de um debate acerca do fenômeno do atrito, debate este que ocorreu no momento de discussão de problemas e de exposição de modelos.

No momento de discussão de problemas, os alunos debateram o problema central, debate este que se fundamentou na solução de três outros problemas que em conjunto, constituíram o problema central. Tais problemas foram os seguintes: influência do peso na mobilidade dos blocos; influência da área de contato na mobilidade dos blocos; influência do polimento das superfícies de apoio na mobilidade dos blocos. Por meio dos referidos problemas, discutiram-se as relações: (1) peso x atrito; (2) dimensão das faces de contato x atrito; (3) polimento x atrito; (4) intensidade do atrito x aceleração do bloco; e (5) natureza do atrito. Um "conjunto conceitual" identificado nas relações entre causa e efeito estabelecidas pelos alunos em suas declarações durante o debate, é explicitado aqui de forma sintética por seis hipóteses. Na seqüência, apresentam-se as hipóteses identificadas durante o momento de discussão de problemas, bem como algumas das declarações dos alunos que justificam uma determinada hipótese.

\section{Hipóteses utilizadas pelos alunos durante o momento de discussão de} problemas.

\section{(2.1) Quanto maior o peso menor a distância percorrida por um bloco}

29) B: O peso aumenta o atrito e por isso o bloco para antes.

30) F: É por causa do peso que ele parou um pouco antes.

31) G: Se você pegar ele assim, (de ponta), você diminui o peso e ele fica mais fácil de empurrar e ai vai mais longe.

32) H: Aqui o pesado ficou e o leve passou por causa do peso deles. 


\section{(2.2) Blocos mais polidos por apresentarem menor atrito percorrerão} distâncias maiores

33) A: Eu acho que é o polimento e não o tamanho do lado que muda o atrito, e por isto é mais fácil empurrar o bloco na parte mais polida, porque nesta parte o atrito é menor.

34) F: Tem um detalhe aqui (observa tocando nos blocos) o mais leve é mais poroso, já o pesado é mais liso, por isso dá mais deslizamento nele.

\section{(2.3) Quanto maior a intensidade da força aplicada ao bloco, maior a distância}

\section{percorrida por ele}

35) A: Quem sair da palma da mão vai mais longe, recebe mais força.

36) D: A distância depende da força que a gente empurrar o bloco.

37) F: É que quando muda de lado ele tem outro lixamento aí muda a força que tem que fazer para empurrar.

\section{(2.4) Quanto menor a área de contato, maior o atrito, e por isto o bloco}

\section{percorre distâncias menores}

38) A: Quando diminui a área de contato, o atrito se torna maior, por isso ele desliza menos (reformulou pela hipótese-2.2).

39) G: Ele deitado é mais fácil de deslizar, agora nesta posição assim, (uma das faces menores como apoio) ele não vai (o bloco tombou durante o experimento). É porque aumenta o atrito, ele tomba fácil.

\section{(2.5) Quanto maior a intensidade do atrito, menor a intensidade da velocidade.}

40) A: Isso (o derrapar) depende da velocidade que ele chega no áspero, se ele vim com menos velocidade ele não derrapa.

41) B: Ele vem em uma alta velocidade e quando chega no áspero vai diminuindo até parar

42) $C:$ A parte que tem mais atrito, ela diminui a velocidade dele.

43) F: Aqui ele ganha o atrito (parte da frente) e para primeiro que aqui (parte de traz) por isso ele vira.

44) G: Quanto mais áspero menos ele corre.

45) I: Ele vira porque essa parte aqui (parte de traz do bloco) está meio rápida no liso quando esta daqui (parte da frente) entra no áspero e diminui a velocidade.

\section{(2.6) Uma grande força é necessária para vencer o atrito da superfície áspera.}

46) A: Para sair do áspero tem que sair com muita velocidade tem que colocar mais força!

47) C: Tem que colocar muita força nele para ele sair do áspero.

48) G: Depende da velocidade que ela sai, ele passa para o outro lado (liso) mais dependendo da velocidade que ele está ele para na parte áspera, por isto que tem que empurrar forte. 
Encerrado o momento de discussão de problemas, o professor por meio dos kits -2 e 3 e do texto (2) expôs aos alunos os modelos de Coulomb e Eletromagnético para o fenômeno do atrito, e relacionou o referido fenômeno ao da aceleração. Tem-se aqui caracterizado o início de exposição de modelos. O professor, após entregar o kit - 3 aos grupos de alunos e permitir que os mesmos o observassem por um tempo, explicou fazendo-os tocarem nos materiais do referido kit, que as superfícies dos materiais representavam superfícies ao nível atômico, ampliadas. Naquele momento o professor, ao solicitar que os alunos tentassem mover o bloco sobre a superfície (materiais do kit - 3) apresentou aos mesmos o modelo de Coulomb para o atrito. Explicou o professor que de acordo com Coulomb: "a causa do atrito deve-se a existência de irregularidades entre as superfícies em contato, que se encaixariam umas nas outras, dificultando o deslocamento relativo entre elas" (GASPAR, 2000). Enfatizou, contudo o professor que o modelo de Coulomb para o atrito não era o mais atual. Visando aprofundar as explicações acerca do tema estudado, ligou o toca CD no texto (2) para que o mesmo fosse ouvido pelos alunos.

Assim que os alunos terminaram de ouvir o texto (2), o professor apresentou-lhes o modelo Eletromagnético para o atrito. Explicou-lhes que a força de atrito entre superfícies rígidas não lubrificadas, deve-se $90 \%$ a forças de adesão, de natureza eletromagnética, e $10 \%$ deve-se aos encaixes e desencaixes sugeridos por Coulomb (GASPAR, op. cit.). Com a finalidade de retomar as relações entre: o atrito e a força normal, o atrito e a área de contato, e o atrito e a aceleração, o professor recapitulou algumas relações estabelecidas anteriormente pelos alunos e que se encontram explicitadas entre as hipóteses (2.1) e (2.6).

O professor enfatizou que alguns alunos haviam observado por meio do tato, que quanto maior a massa do bloco, maior deveria ser a força aplicada a ele para movê-lo sobre as superfícies. Naquele momento, o professor diferenciou os conceitos de massa e peso, conceitos estes freqüentemente compreendidos como iguais. Colocando o texto no trecho que fala sobre a força normal e utilizando-se do kit - 2, o professor organizou e apresentou por meio de explicações orais e táteis, uma das leis empíricas do atrito (lei 2: ver texto (2)) que estabelece uma relação direta entre a força de atrito e a força normal.

Após ter explicado a relação entre força normal e força de atrito, o professor enfocou a relação entre força de atrito e dimensões da área de contato do bloco (primeira lei empírica acerca do atrito: ver texto (2)). Considerando as dificuldades de se observar por 
meio do tato que a força de atrito independe das dimensões da área de contato do bloco, o professor apresentou oralmente a referida lei empírica. Apesar de não trivial, a observação tátil da independência da intensidade da força de atrito das dimensões da área de contato dos blocos, se viu prejudicada pela diferença entre os polimentos das faces dos mesmos. Este fato dificultou a apresentação da primeira lei empírica do atrito.

Finalizando o momento de exposição de modelos, o professor sintetizou as relações entre o atrito, a força normal e a área dos blocos e relacionou a intensidade do atrito ao movimento. Enfatizou as observações táteis dos alunos relacionadas à dificuldade de mover blocos em condições diferenciadas de polimento, e estabeleceu a influência do atrito na mobilidade dos blocos, e por consequiência, em sua aceleração. Em síntese, a relação entre força normal e de atrito, apresentou-se observável para os alunos, e isto facilitou ao professor o estabelecimento da referida relação. Por outro lado, as dificuldades de observação tátil da independência entre a área de contato e a força de atrito, prejudicou a explicação de tal conceito, pois, o referido princípio, chocava-se com as observações dos alunos. Destaca-se como um ponto negativo da mediação do professor, o fato do mesmo não ter trabalhado os conceitos de força de atrito estático e dinâmico. O tratamento desses conceitos foi deixado de lado devido ao esgotamento do tempo reservado para o momento de exposição de modelos. Note-se, contudo, que as explicações do professor somente foram possíveis de serem apresentadas devido à introdução dos referenciais táteis e auditivos contidos nos kits e no CD. As expressões utilizadas pelo professor (elementos da física), não eram desconhecidas dos alunos que observaram e discutiram muitos dos fenômenos sintetizados. Portanto, as explicações orais, o CD, bem como os kits, serviram além de reunir os elementos discutidos, apresentar aos alunos, um modelo para o atrito, bem como, sua relação com o fenômeno da aceleração. Observa-se que apesar do momento de exposição de modelos caracterizarem-se principalmente por procedimentos de mediação do professor, os alunos $(\mathrm{G})$ e $(\mathrm{H})$ apresentaram neste momento algumas declarações relacionadas aos temas expostos pelo docente, declarações estas que ocorreram por ocasião da observação do kit - 3. Algumas dessas declarações foram agrupadas e sintetizadas por meio da hipótese (2.7).

(2.7) $O$ atrito surge dos encaixes e desencaixes entre as saliências existentes nas superfícies em contato mesmo que estas sejam muito polidas. 
49) G: É por isto que ocorre o atrito, note como eles encaixam.

50) H: Todas as superfícies são feitas desses morrinhos, e quando você coloca objetos em contato, olha como surge o atrito.

Um momento denominado: momento de avaliação encerrou a atividade (2). No referido momento, o professor ligou o toca CD na questão avaliação aberta da atividade (2), e permitiu que os alunos refletissem sobre ela. Após terem ouvido a referida questão, os alunos apresentaram algumas soluções para a mesma. $\mathrm{O}$ aluno $(\mathrm{G})$ precisou se retirar da atividade (2) ao final do momento de exposição de modelos, e por isto, não participou do momento de avaliação. As hipóteses (2.8) e (2.9) sintetizam as declarações dos alunos acerca das explicações apresentadas por eles à questão avaliação. Destaca-se que tais explicações foram apresentadas no contexto de um debate no qual os alunos ao mesmo tempo em que expressavam suas opiniões, ouviam as de seus colegas e por este motivo, encontravam-se sujeitos a mudança de opiniões. Contudo, este contexto reflexivoargumentativo será abordado na seqüência.

(2.8) Um objeto em repouso sobre uma superfície sem atrito não necessita da ação de um agente externo para entrar em movimento

51) A: Ele tem que fazer campo, só com os pés dele ele não vai conseguir, ele vai ter que deitar no chão e se movimentar.

52) B: Ou vai rolando ou vai deitado se arrastando.

53) F: Eu acho que tem que deitar e ir rolando.

(Alunos: A, B, e F reformularam a hipótese 2.8 pela hipótese 2.9).

(2.9) Um objeto em repouso sobre uma superfície sem atrito necessita da ação de um agente externo para entrar em movimento

54) A: Me parece que uma das coisas indispensáveis para que eu chegue na margem é o apoio, porque se não, não da para andar, desliza.

55) B: Tem que ser deslizando, mas se a superfície é lisa, não tem como dar impulso!

56) F: Acho que uma das possibilidades de você sair do lago, é soprar o ar com a boca e conseguir um apoio no próprio ar.

57) H: Só se for com a unha, com as garrinhas como gato se vai com a unha, precisa de aderência.

\section{A atividade (2) enquanto ambiente de ensino-aprendizagem.}

Analisando as hipóteses da atividade (2) à luz da categoria compreensão, podem-se explicitar as características das atitudes de compreensão utilizadas pelos alunos durante o 
debate. O quadro (2) apresenta a relação entre cada hipótese e as atitudes de compreensão adotadas pelos alunos.

\begin{tabular}{|c|c|c|c|c|c|c|c|c|}
\hline Alunos: & $\mathbf{A}$ & B & $\mathbf{C}$ & D & $\mathbf{F}$ & G & $\mathbf{H}$ & I \\
\hline (2.1) & $\begin{array}{c}\text { Não } \\
\text { demonstrou } \\
\text { atitude }\end{array}$ & Compartilhou & $\begin{array}{c}\text { Não } \\
\text { demonstrou } \\
\text { atitude }\end{array}$ & $\begin{array}{c}\text { Não } \\
\text { demonstrou } \\
\text { atitude }\end{array}$ & Compartilhou & Compartilhou & Compartilhou & $\begin{array}{c}\text { Não } \\
\text { demonstrou } \\
\text { atitude }\end{array}$ \\
\hline (2.2) & Compartilhou & $\begin{array}{c}\text { Não } \\
\text { demonstrou } \\
\text { atitude }\end{array}$ & $\begin{array}{c}\text { Não } \\
\text { demonstrou } \\
\text { atitude }\end{array}$ & $\begin{array}{c}\text { Não } \\
\text { demonstrou } \\
\text { atitude }\end{array}$ & Compartilhou & $\begin{array}{c}\text { Não } \\
\text { demonstrou } \\
\text { atitude }\end{array}$ & $\begin{array}{c}\text { Não } \\
\text { demonstrou } \\
\text { atitude }\end{array}$ & $\begin{array}{c}\text { Não } \\
\text { demonstrou } \\
\text { atitude }\end{array}$ \\
\hline (2.3) & Compartilhou & $\begin{array}{c}\text { Não } \\
\text { demonstrou } \\
\text { atitude }\end{array}$ & $\begin{array}{c}\text { Não } \\
\text { demonstrou } \\
\text { atitude }\end{array}$ & Compartilhou & Compartilhou & $\begin{array}{c}\text { Não } \\
\text { demonstrou } \\
\text { atitude }\end{array}$ & $\begin{array}{c}\text { Não } \\
\text { demonstrou } \\
\text { atitude }\end{array}$ & $\begin{array}{c}\text { Não } \\
\text { demonstrou } \\
\text { atitude }\end{array}$ \\
\hline (2.4) & $\begin{array}{c}\text { Reformulou } \\
\text { pela hipótese } \\
(2.2)\end{array}$ & $\begin{array}{c}\text { Não } \\
\text { demonstrou } \\
\text { atitude }\end{array}$ & $\begin{array}{c}\text { Não } \\
\text { demonstrou } \\
\text { atitude }\end{array}$ & $\begin{array}{c}\text { Não } \\
\text { demonstrou } \\
\text { atitude }\end{array}$ & $\begin{array}{c}\text { Não } \\
\text { demonstrou } \\
\text { atitudes }\end{array}$ & Compartilhou & $\begin{array}{c}\text { Não } \\
\text { demonstrou } \\
\text { atitude }\end{array}$ & $\begin{array}{c}\text { Não } \\
\text { demonstrou } \\
\text { atitude }\end{array}$ \\
\hline (2.5) & Compartilhou & Compartilhou & $\begin{array}{c}\text { Não } \\
\text { demonstrou } \\
\text { atitude }\end{array}$ & $\begin{array}{c}\text { Não } \\
\text { demonstrou } \\
\text { atitude }\end{array}$ & Compartilhou & Compartilhou & $\begin{array}{c}\text { Não } \\
\text { demonstrou } \\
\text { atitude }\end{array}$ & Compartilhou \\
\hline (2.6) & Compartilhou & $\begin{array}{c}\text { Não } \\
\text { demonstrou } \\
\text { atitude }\end{array}$ & Compartilhou & $\begin{array}{c}\text { Não } \\
\text { demonstrou } \\
\text { atitude }\end{array}$ & Compartilhou & Compartilhou & $\begin{array}{c}\text { Não } \\
\text { demonstrou } \\
\text { atitude }\end{array}$ & $\begin{array}{c}\text { Não } \\
\text { demonstrou } \\
\text { atitude }\end{array}$ \\
\hline$(2.7)$ & $\begin{array}{c}\text { Não } \\
\text { demonstrou } \\
\text { atitudes }\end{array}$ & $\begin{array}{c}\text { Não } \\
\text { demonstrou } \\
\text { atitudes }\end{array}$ & $\begin{array}{c}\text { Não } \\
\text { demonstrou } \\
\text { atitudes }\end{array}$ & $\begin{array}{c}\text { Não } \\
\text { demonstrou } \\
\text { atitudes }\end{array}$ & $\begin{array}{c}\text { Não } \\
\text { demonstrou } \\
\text { atitudes }\end{array}$ & Compartilhou & Compartilhou & $\begin{array}{c}\text { Não } \\
\text { demonstrou } \\
\text { atitudes }\end{array}$ \\
\hline (2.8) & $\begin{array}{c}\text { Reformulou } \\
\text { pela hipótese } \\
(2.9)\end{array}$ & $\begin{array}{c}\text { Reformulou } \\
\text { pela hipótese } \\
(2.9)\end{array}$ & $\begin{array}{c}\text { Não } \\
\text { demonstrou } \\
\text { atitudes }\end{array}$ & $\begin{array}{c}\text { Não } \\
\text { demonstrou } \\
\text { atitudes }\end{array}$ & $\begin{array}{c}\text { Reformulou } \\
\text { pela hipótese } \\
(2.9)\end{array}$ & $\begin{array}{c}\text { Não } \\
\text { demonstrou } \\
\text { atitudes }\end{array}$ & $\begin{array}{c}\text { Questionou } \\
\text { por meio da } \\
\text { hipótese (2.9) }\end{array}$ & $\begin{array}{c}\text { Não } \\
\text { demonstrou } \\
\text { atitudes }\end{array}$ \\
\hline (2.9) & Compartilhou & Compartilhou & $\begin{array}{c}\text { Não } \\
\text { demonstrou } \\
\text { atitude }\end{array}$ & $\begin{array}{c}\text { Não } \\
\text { demonstrou } \\
\text { atitude }\end{array}$ & Compartilhou & $\begin{array}{c}\text { Não } \\
\text { demonstrou } \\
\text { atitude }\end{array}$ & Compartilhou & $\begin{array}{c}\text { Não } \\
\text { demonstrou } \\
\text { atitude }\end{array}$ \\
\hline
\end{tabular}

Quadro (2): Relação para a atividade (2) entre as hipóteses e as atitudes definidas na categoria compreensão.

Verifica-se de acordo com o quadro (2) que ocorreram durante a atividade (2) alguns momentos de questionamentos, defesas, e reformulações de hipóteses. Sobre esses momentos, cabe o seguinte comentário: observou-se por parte do aluno (A) a reformulação da hipótese (2.4) pela hipótese (2.2) e por parte dos alunos (A, B, e F) a reformulação da hipótese (2.8) pela hipótese (2.9), hipótese esta que havia sido questionada pelo aluno $(\mathrm{H})$.

Observando o nível de compartilhamento das nove hipóteses identificadas, nota-se que as relações de proporcionalidade inversa entre, a intensidade do atrito e a da velocidade (hipótese-2.5), e a da intensidade do peso e a distância percorrida (hipótese-2.1), juntamente com a relação de proporcionalidade direta entre a intensidade da força e a intensidade do atrito (hipótese-2.6), mostraram-se significativas dentro do conjunto conceitual utilizado pelos alunos em suas argumentações, já que, as referidas relações foram as mais compartilhadas, além de não serem questionadas por eles. A idéia da necessidade de um agente externo para iniciar um movimento, contida na hipótese (2.9) 
também se mostrou significativa, pois, resultou para três alunos (A, B, e F) de uma reformulação (reformulação da hipótese-2.8 comparar frases: 51x54, 52x55, 53x56).

Destacam-se também, a relação de proporcionalidade direta entre intensidade da força e distância percorrida (hipótese-2.3), relação esta não questionada, e compartilhada pelos alunos (A, D, e F), e a idéia sobre a natureza do atrito contida na hipótese (2.7), idéia esta que não recebeu questionamentos. Cabe ressaltar que a hipótese (2.7) foi identificada a partir das declarações sobre a natureza do atrito que os alunos $(G$, e $H)$ apresentaram durante a mediação do professor por ocasião do momento de exposição de modelos.

Por fim, destacam-se as idéias contidas nas hipóteses (2.2) e (2.4) idéias estas que apresentam causas diferentes para a diminuição do atrito. A hipótese (2.4) relaciona por meio de uma proporção inversa, as dimensões da face do bloco e a intensidade do atrito, enquanto que a hipótese (2.2) relaciona também por meio de uma proporção inversa, o atrito e a intensidade do polimento das faces dos blocos. Destaca-se, contudo, que há em ambas as hipóteses uma relação inversa entre intensidade do atrito e distância percorrida. Os alunos (A, e G) compartilharam inicialmente a hipótese (2.4). Esta por sua vez, foi reformulada pelo aluno (A) que passou a compartilhar a hipótese (2.2). Em outras palavras, o aluno (A) reformulou uma idéia fundamentada numa relação de proporcionalidade inversa entre dimensões da área de contato e intensidade do atrito (hipótese-2.4 frase: 38), por uma idéia fundamentada numa relação de proporcionalidade inversa entre intensidade do atrito e polimento das superfícies dos blocos (hipótese-2.2 frase 33). Observa-se, contudo, que as frases apresentadas em cada hipótese não se encontram em ordem cronológica de acontecimento, e por este motivo, não se deve compreender, por exemplo, a ocorrência do evento representado pela frase 33 como antecedente do evento representado pela frase 38 .

Portanto, enquanto ambiente de ensino-aprendizagem, a atividade (2) proporcionou condições para que os alunos desenvolvessem estratégias para a busca de soluções ao problema central que a eles foi apresentado. Essas estratégias fundamentaram-se na experimentação, e na apresentação de hipóteses que objetivavam explicar o que havia sido observado. As hipóteses para as relações: atrito x peso, atrito x face de apoio, atrito $\mathrm{x}$ aceleração, estabelecidas pelos alunos, deram condições para o professor apresentar a evolução dos modelos sobre a natureza do atrito, e para trabalhar o conceito de 
desaceleração. A referida atividade também se mostrou eficaz em produzir nos alunos questionamentos defesas e reformulações de hipóteses, ações estas relacionadas a efeitos de aprendizagem (WHEATLEY, 1991).

A partir das análises efetuadas, conclui-se que a atividade (2), foi capaz de motivar os alunos e proporcionar aos mesmos condições para que eles: (1) realizassem experimentos sobre o atrito e sobre a aceleração; (2) observassem e analisassem por meio de referenciais auditivos e táteis, propriedades da lei do atrito; (3) observassem e analisassem por meio de referenciais auditivos e táteis, o fenômeno da desaceleração; (4) desenvolvessem estratégias para resolver o problema central; (5) formulassem e expusessem hipóteses durante as discussões do problema central e da questão avaliação, e para a natureza do atrito; e (6)ouvissem por meio do professor ou do texto (2) sínteses relacionadas à natureza do atrito e ao fenômeno da desaceleração.

\section{Conclusão.}

Apresentou-se a análise da aplicação de duas atividades de ensino de física desenvolvidas para alunos com deficiência visual. Como descrito, o conteúdo de tais atividades abordou o conceito de aceleração, bem como, a relação entre tal conceito e o de atrito.

Verificou-se que as atividades proporcionaram as condições para que os alunos estabelecessem discussões reflexivas acerca da relação entre os fenômenos do atrito e da aceleração. Os materiais desenvolvidos para essas atividades mostraram-se eficazes na realização de observações não visuais, o que foi de fundamental importância para a contextualização dos fenômenos do atrito e da aceleração, motivação dos alunos, e para que o professor estabelecesse explicações orais e táteis acerca dos referidos fenômenos.

Assim, em relação às atividades (1) e (2) apresenta-se a seguinte sugestão: em salas de aula de física que tenham a presença de alunos com deficiência visual, a atividade (1) poderia ser utilizada na contextualização do fenômeno do atrito, como por exemplo, no início do estudo do referido conteúdo. Posteriormente a aplicação da referida atividade, uma discussão mais aprofundada acerca do fenômeno do atrito, bem como, de seus efeitos para o movimento de um objeto (atividade-2), poderia ser realizada pelo professor, e dessa 
forma, princípios e leis sobre o tema do atrito poderiam ser trabalhados junto à alunos com deficiência visual.

\section{REFERÊNCIAS BIBLIOGRÁFICAS}

BAUERSFELD, H. Interaction, construction, and Knowledge: Alternative perspectives for mathematics education. In D. Grouws and T. Cooney (Eds.), Perspectives on research on effective mathematics teaching. Reston, VA: National Council of Teachers of mathematics, 1988.

CAMARGO, E.P. O Ensino de Física no contexto da deficiência visual: elaboração e condução de atividades de ensino de física para alunos cegos e com baixa visão. Campinas, Tese. Doutorado em Educação, Faculdade de Educação, Universidade Estadual de Campinas, 2005.

COPELli, A.C., TOSCANO, C., TEIXEIRA, D.R., SILVA, I.S., PEREIRA, J.A., MARTINS, J. MENEZES, L.P.C., PIASSI, L.C., PELAES, S.B., DIAS, W.S., HOSOUME, Y. In: Leituras de Física, (GREF) Grupo de Reelaboração do Ensino de Física, Instituto de Física da USP. Disponível em: www.sbf.if.usp.br/gref, 1998.

GONÇALVES, A.; TOSCANO, C. Física e Realidade. São Paulo: Scipione, 1997. 367 p. $1 \mathrm{v}, 1994$.

LUDKE, M., ANDRÉ, M.E.D.A. Métodos de coletas de dados: observação, entrevista e análise documental: In: Pesquisa em Educação: abordagens qualitativas; Ed Pedagógica e Universitária LTDA; P. 25-44. MANTOAN, M. T. E. (2002). Ensinando a turma todas as diferenças na escola: Pátio - revista pedagógica, ano V, N. 20, fevereiro/abril, P. 18 -23, 1986.

MORALES, M., MORENO, M. Problema en el uso de los terminos cualitativo/cuantitativo en la investigación educativa. Inestigación en la Escuela, 21: 149-157, 1993.

PÉREZ, D.G., ALÍS, J.C., DUMAS-CARRÉ, A., MAS, C.F., GALlEGO, R., DUCH, A.G., GONZÁLEZ, E., GUISASOLA, J., MARTÍNEZ-TORREGROSSA, J., CARVAlHO, A.M.P., SALINAS, J., TRICÁRIO, H., VALDÉS, P.¿Puede hablarse de consenso constructivista en la educación científica? Enseñanza de la Ciência, 18 (1), 1999.

RESNICK, R., HALLIDAY, D. Mecânica da Partícula - I. In: Física: Mecânica Clássica. 4. ed. Rio de Janeiro: Livros técnicos e científicos editora, 1984.

WHEATLEY, G.H. Constructivist perspectives on Science and Mathematics learning, In: Science Education, 75(1), 9-2. 1, 1991. 